\title{
Teachers' Attitudes toward and Use of Translation in the Foreign Language Classroom at Institutions of Higher Education in Croatia
}

\author{
Mladen Marinac \\ Polytechnic of Rijeka, Rijeka, Croatia \\ Iva Barić \\ Faculty of Tourism and Hospitality, Opatija, Croatia
}

\begin{abstract}
The role of translation in the foreign language classroom has been changing, but it still remains a contentious issue. The long-lasting debate whether students of foreign languages might benefit from the use of translation in class might have made practitioners insecure in relation to whether using translation is beneficial or not, what methods are best and when to use translation. The aim of this study is to investigate EFL practitioners' perspective on translation in teaching foreign languages. Specifically, it explores language for specific purposes (LSP) teachers' attitudes toward translation at tertiary-level institutions in Croatia. The data were collected by means of an online questionnaire using snowball sampling method in order to reach a greater number of teachers. The respondents were English, German and Italian LSP teachers from a variety of tertiary-level institutions. The study revealed that in the Croatian context the majority of LSP teachers use translation in language teaching, however, there seems to be a lack of certainty about its usefulness. In addition, LSP teachers' approach to translation appears to be rather traditional given there is no diversity in the methods mentioned.
\end{abstract}

Index Terms - translation in language teaching (TILT), language for specific purposes (LSP), language teaching, assessment

\section{INTRODUCTION}

Since the 1980s there has been an ongoing discussion about the use and role of translation in language teaching (TILT) and there is an ever increasing number of publications on this issue (Pym A., Malmkjaer K. \& Gutierez-Colon M., 2013). However, under the influence of the long period of exclusion from the language classrooms practitioners still do not feel confident about the reasons and ways of implementing translation into their teaching (Macaro, 2005). Although translation is gaining value in the light of an increasing importance of plurilingualism and multilingualism i.e. increasing value of every language we know and because of the adoption of the cognitive approach to learning of building new knowledge on the existing one (L2 on L1), as well as the inclusion of various methods into language teaching to cater to the individual needs of every language learner, there is still no consensus on the importance, aims and ways of implementation of translation into the foreign language classroom (Tekin, 2010; Almoayidi, 2018). Given that practitioners cannot draw clear conclusions from theory or studies, there is a need to get an insight into the current practice and attitudes of LSP teachers toward TILT.

\section{REVIEW OF LITERATURE}

The negative view on TILT generally arises from the negative aspects of the grammar translation method. Probably the most obvious arguments against translation are that it hinders the direct use of the language being learned and therefore influences its production and understanding through L1, and that it is not one of the four skills and, hence, prevents the communicative use of the foreign language (Gündoğdu \& Büyüknisan, 2005). Other objections against TILT include the arguments that translation in itself is a very complex task, which can be slow, demotivating and too demanding for the language learner (Tekin, 2010; Cook, 2010). Its artificiality, that is focus on form rather than meaning, as well as accuracy rather than fluency are further objections against its inclusion into the modern foreign language classroom. Malmkjaer (1998) lists more disadvantages, such as: taking up valuable time to teach the four skills, unnatural, misleading students into thinking that expressions in two languages correspond one-to-one, producing interferences, a bad test of language skills, and only appropriate for the training of translators.

Although there are surely many disadvantages in the uncritical use of TILT, there are applied linguists who advocate its use and demand a more critical discussion. These linguists propose a new view on translation as an inevitable activity in the language learning process and in language use. One of the most prominent in this area are Guy Cook $(2007 ; 2009 ; 2010)$ and Wolfgang Butzkamm $(2003 ; 2011)$, but also Carreres $(2006 ; 2014)$ and Gonzales-Davies (2014). 
Cook $(2007,2010)$ often takes a global and wide perspective in saying that we live in multilingual societies where there is a constant need for switching, mediating and translating between people and various languages and therefore there is a need for including translation into the language classroom and teach the skills language learners will need in every aspect of their lives. Furthermore, if translation is connected to something that is relevant in the world outside the classroom, it could be motivating as well (Cook, 2007). He also claims that "for teachers too, if they know both languages, translation comes naturally as a teaching technique, unless of course they have been 'educated' not to do this." (Cook, 2007, p. 397). But Cook (2007) is cautious in saying that although learners might need translation skills, there seems to be no discussion or research about the benefits of translation for the acquisition of languages. Butzkamm $(2003$; 2011) has a more concrete approach to TILT. He claims that foreign language structures should be taught through direct contrasting with the first language (Butzkamm, 2011). He even goes so far in saying: "the mother tongue is here not a stop-gap or a last resort, but a first resort. The translation is the grammar." (Butzkamm 2011, p. 386). Despite the seeming radicality of this statement, it still appears to be very intuitive and natural that only by comparing certain language structures to the language(s) one already knows it is possible to fully understand how and why these structures are used, especially when one is learning a language outside the community where the language is spoken and has limited opportunity to use it. Carreres (2014) has a similar understanding of TILT as Cook (2007, 2010); she sees translation as an important real-world skill that has a communicative purpose, but claims that there is a need for more and larger experimental studies that explore the usefulness of translation as a language teaching and learning tool (Carreres, 2014). Most arguments for the use of TILT include the claims that it raises awareness about the similarities and differences between the first and target language (Tekin, 2010;Leonardi, 2010; Gündoğdu \& Büyüknisan, 2005), and therefore could prevent interference errors (Tekin, 2010). It could make learners not only more sensitive to lexical and syntactic contrastive aspects, but also to similarities and differences on the discourse level (Tekin, 2010). And if employed critically and with a clear objective, it can include all the other language skills.

\section{A. Practitioners Attitudes and Behaviours toward TILT}

Teachers' attitudes are under numerous influences, not only current trends. Their own learning experience and also their experience as teachers shape their beliefs and teaching styles. Their culture, their teaching context, as well as their personality, play a significant role. As Hall and Cook (2012) pointed out: "what is in vogue in the literature does not necessarily reflect what is actually happening in all parts of the world. In some places, the latest fashion simply does not reach teachers, syllabus designers or text-book writers; in others, there is a significant time lag before a new approach arrives; and elsewhere, new theories may be actively resisted." (p. 272)

For all these reasons practitioners have been using TILT through the years of dismissal of L1 and translation from the language classroom and are still using it in different contexts (Schjoldager, 2004; Kelly \& Bruen, 2014), especially at the secondary level, in large classes (Cook, 2009), and in contexts "where there are not many native speakers of the target language" (Lems, Miller \& Soro, 2010 in Kelly \&Bruen, 2014, p.3). Even though foreign language teaching literature was for decades under the influence of second language acquisition theories, first language acquisition, Skinner's behaviourism, Chomsky's universal grammar theories (Cook, 2009), the direct method and other theories which banned the L1 from foreign language teaching, it does not mean that practitioners were affected. Pym et al. (2013) investigated the role of translation in language teaching in the European Union and conducted various connected studies, among which a rather large study with 896 elementary, secondary and tertiary level language teachers. Their participants stated that grammar translation was the second last favourite teaching method, but that translation is being used in the foreign language classrooms. Their study (Pym et. al., 2013) also showed that translation exercises are used more at tertiary level language learning, than at secondary level and least at primary level, and that teachers with an experience of 20 years or more were more prone to translation exercises. What is interesting is that in some countries (Croatia, Finland and the United Kingdom), there is a tendency of younger teachers to introduce translation exercises into the language classroom.

\section{B. Practitioners Attitudes and Behaviours toward TILT in Croatia}

Given that Croatia is one of the countries which took part in the studies conducted by Pym et al. (2013), some of their main conclusions will be presented here. In the questionnaire most of the Croatian teachers at all levels used translation, but in a mid-to-low frequency. The results also suggest that they have a relatively positive attitude toward translation and that they use it in a rather traditional way (checking grammar and vocabulary), but that they relatively agree with a newer understanding of translation as a fifth skill and that it can bring the other four skills (listening, reading, writing and speaking) together. These positive attitudes might stem from a tradition of investigating the possibilities and problems of the use of TILT in Croatia in the last decades (Zergollen-Miletić, 2014; Mihaljević-Djigunović \& Pintarić, 1995).

\section{METHODOLOGY}

\section{A. Aims}

This study aims to explore the attitudes of LSP teachers toward the use and importance of translation in teaching languages for specific purposes (LSP) at Croatian tertiary-level institutions of higher education. Specifically, the aim is 
to investigate foreign language teachers' self-reported use of translation and their standpoint toward the role of translation in the foreign language teaching classroom.

The research questions which guided the study are as follows:

1) What are LSP teachers' attitudes toward translation in the foreign language classroom?

2) How is translation used in the foreign language classroom at tertiary-level institutions?

\section{B. Participants}

The participants were 40 LSP teachers who work at tertiary-level institutions of higher education in the Croatian context. The anonymous online questionnaire was administered via e-mail using snowball sampling technique. All the respondents are female language teachers. More than a third of the participants (37.5\%) are in the 40-49 age group, followed by 30-39 (27.5\%) and 50-59 (25\%) age groups. Only 5\% of the participants are above 60 or under 30 The respondents' teaching experience varies from 3 to 39 years (18.45 years on average, mode=20, median=18). Most respondents $(22,5 \%)$ have between 16 and 20 years of experience. The respondents teach English, German or Italian, or a combination of these (English and Italian or English and German). An overwhelming majority of the respondents (75\%) teach English for Specific Purposes, a third of the participants (32.5\%) teach German and only 10\% teach Italian. In terms of the profession, more than a third of the respondents (37.5\%) teach Business LSP, which is followed by LSP for Engineers (Marine Engineering, IT, Telematics) (22.5\%), Maritime LSP (15\%), LSP for Tourism (10\%), Medical (7.5\%) and Law LSP (7.5\%). In addition, LSP for Politicians, Kinesiology and Musicians are also taught by one of the respondents.

\section{Research Method}

The responses were collected by means of an online questionnaire written in Croatian in order to reach teachers of different languages and to determine whether there is a difference among these. The questionnaire comprised four parts: sample characteristics, participants' use and attitudes toward translation, translation and assessment and perceived students' and teachers' attitudes toward translation. The first part investigated the participants' personal data in relation to gender, age, teaching experience, languages they teach and professions they teach. This part consisted of two multiple-choice questions and three open-ended questions. The second part enquired into the participants' use of translation - a yes-no question asked the respondents whether they use translation or not. Four multiple-choice questions explored why they use translation, how often they use it within one semester, what the purpose of using translation is and how they use it (translating from mother tongue to the target language, vice versa or both; written and/or oral translation). One open-ended question enquired into translation activities they use in the classroom (types of activities, what they translate), while the remaining two open-ended questions investigated the respondents' views on advantages or disadvantages of using translation in the foreign language classroom. In the third part the participants provided their responses regarding the use of translation in assessment. Specifically, a yes-no question enquired whether the respondents use translation in assessment or not. Two multiple-choice questions investigated what is translated in tests/midterms/ exams (words, phrases, sentences and texts) and what kind of translation is used (from mother tongue to the target language, vice versa or both). The fourth part asked the respondents to rate whether students liked or disliked translation in the classroom using a multiple-choice question. Two open-ended questions asked the respondents to provide answers why they think students like or dislike translation. Finally, a multiple-choice question investigated whether the respondents' teachers used translation in teaching.

\section{RESULTS}

\section{A. Use of Translation in Teaching}

In terms of the use of translation in teaching, the results show that that an overwhelming majority of the participants $(92.5 \%)$ use translation, only the minority $(7.5 \%)$ report they do not use it in their classroom. When asked about the reasons for the use of TILT most of the respondents agreed with the statement that they use it for the purpose of teaching vocabulary $(90 \%)$, followed by teaching grammar $(45 \%)$ and developing the communicative competence (40\%), whereas only $30 \%$ use TILT to develop translational skills, $22.5 \%$ for developing reading competence, and $12.5 \%$ for developing writing skills. More than half of the respondents agreed with the statements that they use TILT to check $(65 \%)$ and facilitate comprehension $(62.5 \%)$. To further clarify the reasons for the use of TILT, the respondents provided numerous and detailed explanations (that were translated from Croatian into English by the authors) and some of these can be divided into the following four categories:

(1) TILT expands vocabulary in $\mathrm{L} 1$ and $\mathrm{L} 2$

$i$. [I use TILT] because there is terminology and maritime jargon that students are not familiar with in the Croatian language.

ii. I use it because it is quite important to me that students are familiar with synonyms in Croatian when they communicate about their profession in Croatian.

(2) TILT helps when dealing with complex terminology

$i$. I believe that technical vocabulary is acquired more easily that way. 
ii. Without translating terminology into the Croatian language, there is no precise understanding of terms in any language.

iii. [ I use TILT] As a help to students in acquiring technical terminology and translation, which they can encounter during their study programmes and at work, in order to facilitate the understanding of terminology.

$i v$. Texts are quite technical and students have a problem dealing with vocabulary.

(3) TILT raises awareness about the similarities and differences between languages and prevents interference errors:

i. [TILT helps in] understanding more complex structures, false pairs in technical English/German.

ii. I use translation only to compare the meanings of certain terms and phrases.

iii. I use to raise awareness comparatively and acquire technical terminology and to get an insight into the differences between the general and language for specific purposes.

$i v$. Students need to become aware of the differences between the two languages in order to avoid literal translation.

Some respondents claim matter-of-factly that "it (translation) is relevant" and "it is efficient". One states she uses translation "because it is an integral part of teaching languages for specific purposes" and another one that it signifies "training students to use foreign literature independently with the aim of finding and recognizing wanted and demanded information". One respondent points out the pragmatic part of using translation by saying "there are tasks and exercises at hand", whereas one warns about the learning goals in LSP "sometimes I deem it useful although translation is not one of the learning goals".

The reasons why translation is not used in the LSP tertiary-level classroom could be grouped into the following categories:

(1) avoiding mother tongue

i. I try to avoid using the Croatian language, [I do it] just in dire need.

(2) TILT is a challenge for both students and teachers:

$i$. Students find that (translation) is a major challenge, which they are frequently not prepared to face, and it represents a big challenge in assessment.

ii. Translation is a skill. Similarly to developing certain skills, we should develop translation skills, as well. Without the necessary knowledge about that skill, translation is boiled down to the task in which we are trying to check the acquisition of the meaning and certain grammatical structures.

iii. These are too demanding teaching activities, especially for those who have just started dealing with language for specific purposes. I believe it would demotivate my students. Although I do not think it is a strategy or technique that cannot contribute to acquiring a foreign language.

(3) TILT is not appropriate for all levels of proficiency:

i. I use translation much more when teaching lower than higher level of learning language for specific purposes. Given that I teach language for specific purposes only at higher levels, I use it in teaching technical terminology and phrases, but I keep it at a minimum.

Other reasons against TILT are that lack of time: "My use of translation is very restricted due to the amount of material prescribed in the syllabus." or knowledge about the reasons and ways of implementing translation into language teaching: "I am not sure whether translation is useful in teaching different language aspects and whether it is and to what extent necessary to develop the very translation skill in students. However, my attitude is based only on intuition, I do not know a lot about translation theory and translation in teaching foreign languages, but I would love to learn. Therefore, I believe your paper is praiseworthy."

\section{B. Frequency of Use of Translation in Teaching}

Nearly a third of the respondents $(29.3 \%)$ report using translation every two lessons and $26.8 \%$ of them say they use translation during every lesson. Only $2.4 \%$ use it once in semester and $10 \%$ of them claim they use translation twice in a semester. The additional comments frequently report translation is used "when needed" or "sometimes". Some respondents state that their use of translation varies depending on the task or study group:

$i$. There is no rule, just sometimes it is a task consciously planned as a translation task; more often that activity imposes itself as a requirement within another task.

ii. Whenever there is a need to compare two terms, twice in a month.

iii. It depends on the study program, I use it every or every two lessons with some students, and however, with other students I use it 3-5 times in a semester (classes are held once a week, two or three hours).

When all the answers are coded into Likert scale responses never, rarely (once or twice in a semester), sometimes ("when needed", "occasionally"), often (every two lessons) and very often (every lesson) more than a third (35\%) of respondents use TILT often, even $27.5 \%$ use it very often, $22.5 \%$ sometimes, and only $15 \%$ rarely or never. When asked whether their language teachers used translation in teaching most of the respondents $(42.5 \%)$ claim their teachers used translation "often" and $10 \%$ of them report they used translation "very often". A third of the participants (32.5\%) claim their teachers used translation "sometimes" and the minority (15\%) think they used it "rarely" or "never".

C. Advantages of Using Translation in Teaching 
The respondents were asked about their opinion on the advantages and disadvantages of translation in language teaching. $77.5 \%$ of our respondents gave an advantage of the use of TILT. More than $60 \%$ of them connect the advantages of the use of TILT with teaching and acquiring vocabulary and believe that the main advantage of translation is that it is the easiest, most efficient method to explain the meaning of a technical expression. Some of their answers can be divided into the following categories of advantages of TILT connected with teaching and acquiring vocabulary:

(1) TILT helps to ensure understanding of technical vocabulary and with explaining and acquiring vocabulary:

i. [TILT ensures ] a more precise understanding of technical terms.

ii. Without precise translation equivalents, there is no vocabulary acquisition in any language.

iii. It is sometimes easier to master technical vocabulary because it does not require wasting time to explain professional terms, which students are familiar with in their mother tongue. It is useful in order to check understanding of complex professional and academic texts, especially if students do not have a well-developed reading skills of advanced texts

(2) TILT helps raising awareness about the similarities and differences between the use of vocabulary in different languages and development of metalinguistic awareness:

$i$. There are many advantages: they learn to compare language structures in different languages by raising awareness that there are no complete synonyms in a foreign language; there is a need to build vocabulary in order to express more precisely; use dictionaries and similar reference material; encouraging thinking about the mother tongue

ii. the ability to compare two languages and determining similarities and differences between them, quick solution to vagueness and easier retention of new terms and phrases.

iii. developing metalinguistic awareness of "language peculiarities" and their specificities that do not have a $100 \%$ equivalent in a second language.

A small number of respondents move away from vocabulary when describing the advantages of TILT. Next to vocabulary, two respondents mention that it helps in acquiring and practicing grammar. Three believe it can give feedback on and certainty in proper understanding. For some, the task of translating in itself is an advantage since the learner is the sole active participant. One respondent believes that through the use if TILT "students have to be actively involved in work, they have to understand the meaning of text". Others claim that it helps in the "active mastering of a language" and enables "real situations" to be involved in language teaching. Only two mentioned communicative competence as being an advantage of the use of TILT ("developing communication competences, raising awareness of various conceptualization of synonyms, raising awareness of conventions to structure different texts.").

Some respondents also believe that one of the advantages of using translation is that it shows precisely the status of their students' knowledge. One respondent describes it as "the most reliable assessment of mastering sentence structure, vocabulary and grammatical structures of a foreign language." and another believes that through translation "one gets a comprehensive overview of the knowledge of the language. It is easier to diagnose problems, that is, parts of a language the student has still not mastered".

\section{Disadvantages of Using Translation in Teaching}

Less than half (47.5\%) of the respondents listed a disadvantage of the use of TILT, while a number of them (17.5\%) believe that given the right approach to translation, there are no disadvantages to using it. The described negative aspects of the use of TILT can be divided into five groups of disadvantages: 1) using mother tongue instead of L2, 2) it is time-consuming, 3) it is not amusing, 4) it demands more training in translation 5) less focus on global understanding.

And while one respondent claims that the main disadvantage of the use of TILT is that translation is " $a$ drill task that is not mentally challenging for students", another says that it is "demanding and requires good preparation and knowledge (grammar, vocabulary)." And yet another sees a problem in that translation is a task that requires "constant monitoring of the process and outcomes" otherwise it can lead to interference.

\section{E. Respondents' Perception of Students' Attitudes toward Translation}

The respondents were also asked about their opinion on whether their students liked or disliked translation and what they think why that is so. Most of the respondent (38.5\%) think that their students do not have a strong opinion about translation, whereas even more than $20 \%$ of respondents were undecided about their students attitudes. $28.2 \%$ believe their students like translation and only $10 \%$ think their students do not like it. The most common answer in relation to the question why students like translation is that it is an efficient, straightforward method that helps students grasp new vocabulary easily:

i. It facilitates understanding of business terminology.

ii. They get quickly to the desired answer they are looking for. They do not achieve communication goals, but precious time is not wasted on explaining technical terminology.

iii. It enables the understanding of the unit and comparing expressions in different languages they know.

A good command of translation skills is another explanation given by the respondents on why students like translation. Naturally, those who are good at translation enjoy it and like showing their strengths. Also, it enables those students to hone their syntax. Finally, given that they are good at translation, it increases their motivation to pursue their learning goals: 
One respondent mentions that students like translation due to its nature - it gives them a sense they have done something concrete. Their results are quite tangible because they can see the proof of their knowledge and efforts: "It gives them the feeling of certainty and accomplishment"

Another respondent believes that students like translation because it is easier to translate than to use English. Also, they think that students like it because they are aware of the fact that translation will be part of their future jobs and they do not perceive the activity as translation, but as part of teaching and assessment:

The majority of those respondents who believe that students do not like translation think it is because students find it tedious. In addition, they stress that it depends on the way translation is introduced in the classroom. They warn that it should be done in combination with other teaching methods and teachers should spend a limited amount of time translating:

i. It's not very amusing.

ii. It's not fun.

iii. It is boring, therefore, translation should be introduced in "small amounts" and combined with other teaching activities.

iv. It is monotonous if it is done as a lecture-style instruction.

Also, the respondents hold that translation is a very demanding task, sometimes too challenging for students to enjoy the activity and benefit from it. The participants think it presents an endeavour because it requires substantial prior knowledge and a lot of dedication. The respondents highlight students' lack of knowledge of Croatian terminology to conduct this activity, too. It seems that the frequent usage of English expressions in everyday life makes Croatian equivalents sound contrived:

$i$. I believe it is a great challenge.

ii. It is sometimes tedious, but also difficult, for example translating parts of business letters from their mother tongue to a foreign language.

iii. It is difficult for them to retrieve technical terms in Croatian and frequently they find these funny.

iv. Students who do not like translation are those with poor prior knowledge.

$v$. They have to think and be involved in classroom activities.

vi. It demands using various activities and a lot of time.

One respondent claims that it is normal their students do not enjoy translation given they have chosen to be involved in a different line of work by saying "they did not want to study languages, they wanted to be engineers."

\section{F. Respondents' Ways of Implementing TILT}

Almost two-thirds of the respondents $(65 \%)$ provided a short description of their ways of implementing translation tasks into language teaching and almost all described rather traditional tasks of direct written or oral translation of words, phrases, sentences or texts:

i. Direct translation of a term that students do not know.

ii. Translation of the sentence, translation of vocabulary units.

iii. Translating words and phrases when introducing a new vocabulary.

$i v$. Translation of isolated sentences, translation of the text.

v. Translating technical texts from German to Croatian, translating conversations from Croatian to German.

Only one respondent provided a slightly different description of a translation task in which the students read a text in L1 and need to write a summary in L2. Translation tasks of most of the respondents include translation of vocabulary $(94.9 \%)$, followed by the translation of phrases $(79.5 \%)$ and sentences $(69.2 \%)$, whereas almost half $(47.2 \%)$ of the respondents use translation tasks in which texts are translated. Almost all respondents $(97,4 \%)$ use oral translation tasks, whereas $76.9 \%$ use written translation tasks and the majority of them use translation tasks in both directions, with a slight favour for L2 to L1 translation (94.9\% translate L2 to L1, 84.6\% translate L1 to L2). Most of the respondents claim that translations are carried out individually by their students $(76.9 \%)$, more than a half $(53.8 \%)$ state that the translations are carried out in pairs and less than half use group work (48.7\%) or the frontal approach (46.2\%) for translation in language teaching. When asked about the use of translation in assessment even $75 \%$ of the respondents confirmed using it. The large majority include translation of vocabulary/terminology (81.3\%) into assessment, followed by the translation of sentences $(59.4 \%)$, phrases $(56.3 \%)$ and texts $(28.1 \%)$. During assessment, translation tasks are carried out in both directions. $90.6 \%$ claim using L1 to L2 translations, while $84.4 \%$ include translation from L2 to L1.

\section{DISCUSSION}

In line with a previous study (Pym et. al., 2013) on the use and attitudes toward translation in the Croatian foreign language teaching context, this study shows that Croatian foreign language teachers at the tertiary level have a positive attitude toward TILT and that they use it in their language classes. The results of this study show that in the context of teaching languages for specific purposes at Croatian institutions of higher education an overwhelming percentage (over $90 \%$ ) of teachers use translation as a teaching method and they use it in a mid to high frequency similar to the reported use of their teachers. The high percentage is surprising since this method is still one of the least favourite among other methods (Pym et. al., 2013). And although almost all of the respondents use TILT, some of them are insecure about its 
effectiveness: '...my attitude is based only on intuition, I do not know a lot about translation theory and translation in teaching foreign languages, but I would love to learn..., 'I am not sure whether translation is useful in teaching different language aspects...'

This reflects the current lack of large-scale empirical studies that would give more information about the usefulness of TILT in comparison to other language teaching methods (Carreres, 2014). In this study the main reasons for the use of TILT are teaching vocabulary (90\%) and checking and facilitating comprehension, which shows that Croatian university teachers look at translation from a more traditional point of view, but that they also see the most benefits when using TILT for these purposes. This is supported by the fact that more than a half of those who listed advantages of the use of TILT mentioned that translation is the best method for teaching technical vocabulary because it is efficient and not time consuming. This is especially typical for the LSP context where terminology represents an important part of the teaching content. Due to this reason, the results are perhaps not replicable to other language teaching contexts.

Almost a half of the respondents $(40 \%)$ claim that their reason for the use of TILT is to develop communicative competence, still, only two of the respondents mentioned communicative competence when describing the advantages of the use of TILT, which might suggests that some see a bigger potential in the use of TILT aside from aiding vocabulary acquisition, but are not sure whether its advantages can be compared to the advantages of other methods or are not sure how to use it for this purpose. This, of course, cannot be clearly stated, since they were not asked to compare translation to other teaching methods. It is clear, however, that there were more respondents (77.5\%) who listed advantages of the use of TILT than those who listed disadvantages $(47.5 \%)$. The most frequently mentioned advantage is its usefulness in vocabulary teaching and learning and its role in developing metalinguistic awareness, while the listed disadvantages include arguments that through TILT the process of language learning is unnecessarily focusing on L1, that translation tasks are time-consuming and boring, that one requires special training in translation to be able to use it and that it turns the focus onto detail i.e. a too analytical approach to language learning and teaching.

The results of the study further suggest that in the Croatian LSP context translation is used in a rather traditional manner - direct translations of words, phrases and sentences. Only one respondent reported on using a more alternative and creative translation task. This might indicate that foreign language practitioners are not familiar with more innovative approaches to the use of translation tasks and that there is a need for drawing on the findings from translation studies (Carreres, 2006) and translator education whose experts can provide a long list of useful and creative translation tasks for language teaching. And while, according to Leonardi (2010), translation can promote collaborative learning and is well suited for teamwork and joint problem solving, most of the respondents in this study claim that in their classes translation is done individually, whereas a little more than a half use pair work for translation tasks and a little less than a half assign translation tasks as group work activities.

One of the limitations of the study is that a more detailed questionnaire should have been developed to give more precise data about the attitudes and use of TILT and that no Likert-scale questions were used and therefore no correlation between the answers could be found. Another limitation of this study is that in the questionnaire and therefore in the participants' answers no differentiation was made between mere L1 use in language teaching and the use of translation as a pedagogical tool. This is a general problem of the theory and research on TILT and further discussion about the differentiation and defining these two should take place.

\section{CONCLUSION}

This study shows that translation is an integral part of teaching LSP in the Croatian tertiary context but that there is no certainty about its usefulness other than in vocabulary teaching and learning. Also, there is an overall lack of a more innovative approach to its implementation into the language learning classroom. Therefore, further investigations into this topic should be made, further discussions should be opened up and a closer look should be taken into the findings of translation studies to clarify how to use TILT best to upgrade language learning in general and LSP teaching in particular.

\section{APPENDIX. QUESTIONNAIRE}

Translation in Teaching Languages for Specific Purposes

1) Gender

\begin{tabular}{|l|l|}
\hline Male & \\
\hline Female & \\
\hline
\end{tabular}

2) Age

\begin{tabular}{|l|l|}
\hline$<30$ & \\
\hline $30-39$ & \\
\hline $40-49$ & \\
\hline $50-59$ & \\
\hline $60<$ & \\
\hline
\end{tabular}


3) Number of years in teaching foreign languages:

4) What language(s) do you teach (e.g. English, German, Italian, etc.)?

5) What language of specific purpose do you teach (e.g. medical, law, business, etc.)?

6) Do you use translation in teaching languages for specific purposes?

\begin{tabular}{|l|l|}
\hline Yes & \\
\hline No & \\
\hline
\end{tabular}

7) Why do (not) you use translation in teaching languages for specific purposes?

8) If you use translation, how often do you use it during a semester? (Mark only one)

\begin{tabular}{|l|l|}
\hline never & \\
\hline once in a semester & \\
\hline twice in a semester & \\
\hline every two lessons & \\
\hline every lesson & \\
\hline Other: & \\
\hline
\end{tabular}

9) Why do you use translation? (Check all that apply)

\begin{tabular}{|l|l|}
\hline to teach translation skills & \\
\hline to teach/practice vocabulary & \\
\hline to teach/practice grammatical structures & \\
\hline to develop reading skills & \\
\hline to develop writing skills & \\
\hline to develop communicative competence & \\
\hline to check understanding & \\
\hline to help with understanding & \\
\hline Other: & \\
\hline
\end{tabular}

10) What language do you translate to when teaching foreign languages? (Check all that apply)

\begin{tabular}{|l|l|}
\hline from mother tongue to a foreign language & \\
\hline from a foreign language to mother tongue & \\
\hline
\end{tabular}

11) What type of translation do you use? (Check all that apply).

\begin{tabular}{|l|l|}
\hline Oral & \\
\hline Written & \\
\hline
\end{tabular}

12) If you use translation in class, what kind of activities do you use? Describe briefly.

13) The activities include the translation of: (Check all that apply)

\begin{tabular}{|l|l|}
\hline words/terms & \\
\hline phrases & \\
\hline sentences & \\
\hline texts & \\
\hline Other: & \\
\hline
\end{tabular}

14) Translation activities are carried out (Check all that apply):

\begin{tabular}{|l|l|}
\hline individually & \\
\hline in pairs & \\
\hline in groups & \\
\hline frontal & \\
\hline
\end{tabular}


15) Do you use translation in language assessment?

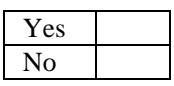

16) Language assessment involves the translation of (Check all that apply):

\begin{tabular}{|l|l|}
\hline terms & \\
\hline phrases & \\
\hline Sentences & \\
\hline texts & \\
\hline Other: & \\
\hline
\end{tabular}

17) Students in language assessment translate (Check all that apply):

\begin{tabular}{|l|l|}
\hline from mother tongue to a foreign language & \\
\hline from a foreign language to mother tongue & \\
\hline
\end{tabular}

18) What are the advantages of using translation in teaching foreign languages?

19) What are the disadvantages of using translation in teaching foreign languages?

20) In your opinion, students (mark only one):

\begin{tabular}{|l|l|}
\hline like translation & \\
\hline do not like translation & \\
\hline neither like nor dislike & \\
\hline I cannot tell & \\
\hline
\end{tabular}

21) Students like translation because... (Finish the sentence)

22) Students do not like translation because... (Finish the sentences)

\section{REFERENCES}

[1] Almoayidi, K. A. (2018). The Effectiveness of Using L1 in Second Language Classrooms: A Controversial Issue. Theory and Practice in Language Studies 8.4, 375-379.

[2] Butzkamm, W. (2003). We only learn language once. The role of the mother tongue in FL classrooms: death of a dogma. The Language Learning Journal 28.1, 29-39.

[3] Butzkamm, W. (2011). Why Make Them Crawl If They Can Walk? Teaching with Mother Tongue. RELC Journal 2011 42.3, 379-391.

[4] Carreres, A. (2006). Strange bedfellows: Translation and language teaching. The teaching of translation into L2 in modern languages degrees: Uses and limitations. In Sixth Symposium on Translation, Terminology and Interpretation in Cuba and Canada. Canadian Translators, Terminologists and Interpreters Council. http://www.cttic.org/publications_06Symposium.asp (accessed 15/1/2018).

[5] Carreres, A. (2014). Translation as a means and as an end: reassessing the divide. The Interpreter and Translator Trainer 8.1, 123-135.

[6] Cook, G. (2007). A thing of the future: translation in language learning. International Journal of Applied Linguistics 17.3, 396401 .

[7] Cook, G. (2009). Use of translation in language teaching. In Baker, M., Saldanha, G. (eds.), Routledge encyclopedia of translation studies (2nd ed.). Abingdon and New York: Routledge, 112-115.

[8] Cook, G. (2010). Translation in Language Teaching: An Argument for Reassessment. Oxford: Oxford University Press

[9] Dudley-Evans, T. \& St. John, M. (1998). Developments in ESP: A multidisciplinary approach. Cambridge: CUP.

[10] González Davies, M. (2014). Towards a plurilingual development paradigm: from spontaneous to informed use of translation in additional language learning. The Interpreter and Translator Trainer 8.1, 8-31.

[11] Gündoğdu, M., \& Büyüknisan, E. (2005). Übersetzung im DaF-Unterricht. In Tagungsbeiträge zum IX. türkischen Germanistik-Symposium.,,Wissen-Kultur-Sprache und Europa “.-Neue Konstruktionen und Neue Tendenzen. Eskişehir, 188197.

[12] Hall, G. \& Cook, G. (2012). Own-language use in language teaching and learning: state of the art. Language Teaching 45.3, 271-308.

[13] Kelly, N. \& Bruen, J. (2014). Translation as a pedagogical tool in the foreign language classroom: A qualitative study of attitudes and behaviours. Language Teaching Research 19.2, 150-168.

[14] Lems, K., Miller, L. \& Soro, T. (2010). Teaching Reading to English Language Learners: Insights from Linguistics. New York: Guilford Publications. 
[15] Leonardi, V. (2010). The role of pedagogical translation in second language acquisition: From theory to practice. Bern: Peter Lang.

[16] Macaro, E. (2005). Codeswitching in the L2 Classroom: A Communication and Learning Strategy. In: Llurda, E., (ed.), NonNative Language Teachers: Perceptions, Challenges, and Contributions to the Professions. New York: Springer, 63-84.

[17] Malmkjaer, K. (1998). Translation and Language Teaching. In Malmkjaer, K., (ed.), Language Teaching and Translation. Manchester, U.K.: St. Jerome Publishing, $1-87$.

[18] Mihaljević Djigunović, J. \& Pintarić, N. (eds.) (1995). Prevođenje - suvremena strujanja i tendencije. Zagreb: HDPL.

[19] Schjoldager, A. (2004). Are L2 learners more prone to err when they translate? In Malmkjær, K. \& McEnery, A.E. (eds.), Translation in Undergraduate Degree Programmes. Amsterdam: John Benjamins, 114-127.

[20] Pym A., Malmkjaer K. \& Gutierrez-Colon M. (2013). Translation and language learning: The role of translation in the teaching of langauges in the European Union. Luxemburg: Publications Office of the European Union.

[21] Tekin, Ö. (2010). Übersetzen im Bereich Deutsch als Fremdsprache: Leistungen, Grenzen und Kon-se--quenzen [Yabancı Dil olarak Almanca Öğretimi Alanında Çeviri - Ve-rimler, Sınırlar- ve So--nuçlar], Eğit, Yadigar (ed.), Globalisierte Germanistik: Sprache - Literatur - Kultur. Ta-gungs-beiträge des XI. Türkischen Internationalen Germanistik Kongress in Izmir, 20.22.05.2009. Izmir: Universitätsverlag, 496-511.

[22] Zhang, J. \& Pang, Y. (2014). Mirroring, reformulation and functional translation. A complementary TEFL model for advanced learners. The Interpreter and Translator Trainer 8.1, 52-69.

[23] Zergollern-Miletić, L. (2014). Translation in Language Teaching: A Few New Thoughts. In J. Horváth \& P. Medgyes (eds.). Studies in Honour of Marianne Nikolov. Pecs: Lingua Franca Csoport, 487-497.

Mladen Marinac graduated from the Faculty of Humanities and Social Sciences, University of Rijeka with a BA in English Language and Literature and an MA in TEFL. Currently he is a PhD candidate in Foreign Language Teaching at the University of Zagreb, Croatia. He teaches ESP courses at the Polytechnic of Rijeka, Croatia and has taught EFL in elementary schools and in language schools. His research interests include ESP, EIL and translation in language teaching.

Iva Barić graduated from the Faculty of Humanities and Social Sciences, University of Rijeka with a B.A. in German Language and Literature and English Language and Literature and an M.A. in German Language and Literature and English Language and Literature -Teaching Track. She teaches German LSP courses at the Faculty of Tourism and Hospitality, Opatija, Croatia and EFL in elementary schools. Currently she is a $\mathrm{PhD}$ candidate in Foreign Language Teaching at the University of Zagreb, Croatia. Her research interests are LSP and L1 use in foreign language teaching. 